\title{
Should I stay or should I go? Initiation of joint travel in mother- infant dyads of two chimpanzee communities in the wild
}

\author{
Marlen Fröhlich ${ }^{1} \cdot$ Roman M. Wittig ${ }^{2,3} \cdot$ Simone Pika $^{1}$
}

Received: 3 July 2015/Revised: 23 November 2015/Accepted: 11 December 2015/Published online: 1 February 2016

(C) The Author(s) 2016. This article is published with open access at Springerlink.com

\begin{abstract}
It is well established that great apes communicate via intentionally produced, elaborate and flexible gestural means. Yet relatively little is known about the most fundamental steps into this communicative endeavour-communicative exchanges of mother-infant dyads and gestural acquisition; perhaps because the majority of studies concerned captive groups and single communities in the wild only. Here, we report the first systematic, quantitative comparison of communicative interactions of mother-infant dyads in two communities of wild chimpanzees by focusing on a single communicative function: initiation of carries for joint travel. Over 156 days of observation, we recorded 442 actions, 599 cases of intentional gesture production, 51 multi-modal combinations and 80 vocalisations in the Kanyawara community, Kibale National Park, Uganda, and the Taï South community, Taï National Park, Côte d'Ivoire. Our results showed that (1) mothers and infants differed concerning the signal frequency and modality employed to initiate joint travel, (2) concordance rates of mothers' gestural production were
\end{abstract}

Electronic supplementary material The online version of this article (doi:10.1007/s10071-015-0948-z) contains supplementary material, which is available to authorized users.

Marlen Fröhlich

mfroehlich@orn.mpg.de

1 Humboldt Research Group 'Evolution of Communication', Max Planck Institute for Ornithology, Eberhard-GwinnerStraße 9, 82319 Seewiesen, Germany

2 Department of Primatology, Max Planck Institute for Evolutionary Anthropology, Deutscher Platz 6, 04103 Leipzig, Germany

3 Taï Chimpanzee Project, Centre Suisse de Recherches Scientifiques, BP 1303, Abidjan 01, Côte d'Ivoire relatively low within but also between communities, (3) infant communicative development is characterised by a shift from mainly vocal to gestural means, and (4) chimpanzee mothers adjusted their signals to the communicative level of their infants. Since neither genetic channelling nor ontogenetic ritualization explains our results satisfactorily, we propose a revised theory of gestural acquisition, social negotiation, in which gestures are the output of social shaping, shared understanding and mutual construction in real time by both interactants.

Keywords Communication - Gestures - Acquisition · Social negotiation - Chimpanzee $\cdot$ Pan troglodytes verus . Pan troglodytes schweinfurthii

\section{Introduction}

Across cultures and languages, human children enter language hands first. It has been hypothesised that this brief period in human ontogeny recapitulates phylogeny, with gestures being the modality out of which human language may have blossomed (for an overview, see Hewes 1973). This so-called gesture-first hypothesis especially inspired comparative researchers to search for evolutionary precursors to human language in non-human primate gesturing (Tomasello 2008). Systematic studies in the last decades have shown that gestures indeed are used as intentionally produced, elaborate and flexible communicative strategies and play, similar to vocalisations, a crucial role in great apes' everyday communication (for overviews, see Call and Tomasello 2007; Pika and Liebal 2012). While there is a large body of work focusing on the description of gestural repertoires in a variety of different primate species (Call and Tomasello 2007; Genty et al. 2009; Hobaiter and 
Byrne 2011), usage of distinct gesture types (Leavens et al. 1996; Pika and Mitani 2006) and cognitive mechanisms underlying gestural signalling (Genty and Zuberbühler 2014; Liebal et al. 2004; Pika and Mitani 2006; Roberts et al. 2014b), surprisingly little is known about the first step into this communicative endeavour: mother-infant coordination as co-regulated social interaction (King 2004).

A large body of research has been emphasising the benefit of conceptualising the mother-infant dyad as a system decades ago (for a review, see van de Rijt-Plooij and Plooij 1987). This system assumes that the motherinfant dyad behaves as an organised whole characterised by mutual modification of each other's behaviour in response to feedback (Watzlawick et al. 1967). Pioneering work has been carried out by Plooij $(1978,1979) 40$ years ago, who investigated gestural ontogeny in mother-infant communication in chimpanzees at Gombe, Tanzania. He showed that, similar to communicative development in human children, interactions between chimpanzee infants and their mothers slowly progress, with a shift around the ages of 9-12 months from acts without social-communicatory intention to intentional acts. At this age, the infant is able not only to maintain an interaction, e.g. 'play-tickling', but also to initiate it by using behaviours whose values have been established in earlier sessions (Plooij 1978). Plooij thus concluded that gestures in chimpanzees do not represent innate signals but are acquired through a process of 'social negotiation' (also termed 'conventionalisation'; Mead 1910). This idea was later developed into a formal hypothesis, 'ontogenetic ritualization' (OR), in which the forms that gestures take derive directly from repeated social interactions in which individuals participate (Tomasello et al. 1994). Thus, evidence for the process of OR would be high degrees of individual variation within dyads, groups and between communities but also concerning the means used to achieve the same goals. Halina and colleagues (2013) recently investigated mother-infant coordination for the purpose of joint travel (carries) in captive bonobo (Pan paniscus) mother-infant dyads and were able to attribute the process of OR to several carry-initiating gestures. This study, thus, supported the hypothesis of Tomasello and colleagues (1994; Call and Tomasello 2007 ) that gestures are acquired via repeated social interactions. For current purposes, the term individual learning refers to a process in which two or more individuals independently acquire the same behaviour due to 'similar learning environments' (Whiten and Ham 1992). Contrarily, the term social learning is used to indicate situations in which individuals learn distinct behaviours by imitating (Bandura 1986) but also by interacting and observing each other. Recently, Byrne and colleagues (Genty et al. 2009; Hobaiter and Byrne 2011) challenged the idea that learning plays a role in great ape's gestural production and suggested that similarly to vocal production and facial expressions, gestures appear hard-wired and can be explained as a result of genetic channelling during development alone. This hypothesis is in contrast to great apes' high degree of manual flexibility in other behavioural domains such as food processing and tool use, and considerable inter-site variability (Byrne et al. 2011; van Schaik et al. 2003; Whiten et al. 1999). However, since systematic quantitative comparisons of gestural signalling in wild populations are still lacking, the absence of evidence might merely reflect a paucity of data, rather than a lack of gestural complexity on behalf of the apes.

The aim of the present study was to gain a better understanding of the complexity and variability of communicative exchanges of mother-infant dyads and to shed light on gestural acquisition. To do so, we enabled the first systematic quantitative comparison of gestural signalling in two chimpanzee communities of different subspecies in their natural environments (Kanyawara, Kibale National Park, Uganda, and Taï South, Taï National Park, Côte d'Ivoire). Since other studies (Halina et al. 2013; Plooij 1978) had suggested that the communicatory context of joint travel represents a promising candidate for frequent communicative exchanges between mother-infant dyads about a distinct goal (leaving a location), we focused our research efforts on this single communicative function. To enable horizontal comparisons between individuals of different communities and vertical comparisons of the same individuals, behavioural data were collected in two consecutive years. This important methodological tool for understanding the cognitive prerequisites underlying different communicative skills had so far only been employed in captive settings (Pika et al. 2003; Schneider et al. 2011; Tomasello et al. 1997).

We addressed the following three questions:

First, which behaviours do chimpanzees employ to initiate joint travel? Plooij (1978), for instance, had noted that mothers who initiate joint travel (1) lower their bottoms, (2) look back at their infants, (3) reach back towards him/ her and (4) make tonal grunts. They thus employ a complex set of gestures (LOWER BACK, LOOK BACK, REACH BACK ${ }^{1}$ ) and multi-modal combinations (LOOK BACK and GRUNT) to communicate the distinct goal of joint travel and also the direction to travel to. To investigate this question, we compiled individual repertoires of behaviours produced to initiate joint travel and analysed signal production in terms of gesture category (e.g. visual or tactile) and signal modality (gesture, vocalisation or combinations of the two, i.e. multi-modal signals). We expected chimpanzee mothers in the wild to be the main carry initiators, thereby

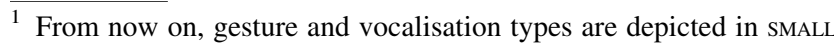
CAPITALS.
} 
contributing the majority of travel-initiating behaviours (van Lawick-Goodall 1967).

Second, are gesture types employed to initiate joint travel due to learning (including both individual and social learning) between mothers and infants or can their production simply be explained as a result of genetic channelling? Since it is impossible to observe developmental processes as they unfold over time under natural conditions, a window approach onto gesture acquisition was applied: We investigated the degree of variability in gestural production to initiate joint travel within dyads within communities and between communities (Pika et al. 2003, 2005). Furthermore, since the presence of idiosyncratic gestures is a key indicator of individual learning and evidence against a phylogenetic origin of gestures, we examined whether idiosyncratic gestures were employed (found to be used by only a single individual of the whole community over two subsequent years and study periods). Pronounced variability in individual gestural production across dyads and communities (e.g. low concordance rates between individuals' repertoires and idiosyncratic gestures) would provide evidence for the impact of learning in mother-infant communication, whereas high rates of concordances in gestural variability across dyads and communities may imply genetic channelling.

Third, do chimpanzee mothers adjust their behaviour to the developmental stage of their infants, and how does infant age influence signal production in both mothers and infants? As suggested by Plooij (1978), the means mothers employ to communicate with their infants might be influenced by the developmental shift from actions to intentional communication in young chimpanzees. In addition, a mother's accumulated experience in interactions with previous offspring might also shape the carry interaction substantially, as well as the prevailing behavioural context (i.e. varying necessity to carry). For instance, while frequent gestural interactions can often be observed in evolutionarily non-urgent, or 'relaxed', situations (e.g. playing and grooming; Pika 2014; van Lawick-Goodall 1967), they sometimes outrival vocalisations in evolutionary 'urgent' contexts, where silent communication transfer is an advantage (e.g. consortship; Hobaiter and Byrne 2012).

\section{Methods}

\section{Study sites and subjects}

The study investigated the communicative behaviour of mother-infant dyads in two different chimpanzee communities: Kanyawara in Kibale National Park, Uganda (Pan troglodytes schweinfurthii), and Taï South in Taï National Park, Côte d'Ivoire (P. t. verus). Detailed descriptions of the study areas can be found in Wrangham and colleagues (1992) and Boesch and Boesch-Achermann (2000). During the two study periods, the size of the Kanyawara group varied between 53 and 56 individuals, respectively, 21 and 24 in Taï South. The Kanyawara and Taï chimpanzees are well habituated and have been studied regularly since 1987 (Wrangham et al. 1992) and 1979 (Boesch and Boesch-Achermann 2000), respectively, enabling dawn-till-dusk follows and the collection of highquality recordings. In addition, we had access to long-term data concerning the chimpanzees' demography, social relationships, relatedness and ranks. We observed communicative interactions of a total of 13 mother-infant dyads (seven from Kanyawara and six from Taï South), with offspring ranging from 9 to 69 months of age (see Table 1). At Taï one mother gave birth to another infant in the second field period; hence, we observed 12 chimpanzee mothers and 13 infants.

\section{Data collection}

Observations were made on chimpanzees of the Kanyawara community in Kibale National Park and the Taï South group at Taï National Park during four periods between October 2012 and June 2014 (Kanyawara: March-May 2013, March-June 2014; Taï South: October-December 2012, October-December 2013). We used a focal behaviour sampling approach (Altmann 1974), while maintaining a record of the frequency with which a particular dyad had been observed. In situations where we could choose which of several dyads to film, we targeted those individuals previously sampled least often. Following Hobaiter and Byrne (2011), who had suggested that approximately $15 \mathrm{~h}$ of active gesture time or approximately 150 days of field observation time would enable to assess the whole gestural repertoire of a given chimpanzee community $(N=82)$, we observed all 13 mother-infant dyads for a total of 156 days. All social interactions of mothers and infants (i.e. mother-infant interactions as well as mother-conspecific and infant-conspecific interactions) that were judged to have any potential for communicative interactions were recorded using a digital high-definition camera (Canon HF M41) with an external unidirectional microphone (Sennheiser K6). This method resulted in a total of $169 \mathrm{~h}$ of video footage recorded during approximately $1198 \mathrm{~h}$ of focal observations (see Table 1 for further details). However, the present paper focuses only on the communicative context of carry initiation; thus, our analysis is based on a total of 410 high-quality recordings of mother-infant behaviour in this respective context (mean recordings per dyad: 33.2). In addition, every 15 min we conducted a focal scan by using a Personal Digital Assistant (HP iPAQ rx1959) with focal/time 
Table 1 Information on observed mother-infant dyads with respective observation time and raw data set

\begin{tabular}{|c|c|c|c|c|c|c|}
\hline Study site & $\begin{array}{l}\text { Dyad } \\
\text { (infant/mother) }\end{array}$ & $\begin{array}{l}\text { Infant } \\
\text { sex }\end{array}$ & $\begin{array}{l}\text { Infant age P1 } \\
\text { (months) }\end{array}$ & $\begin{array}{l}\text { Infant age P2 } \\
\text { (months) }\end{array}$ & $\begin{array}{l}\text { Observation time } \\
\text { (h) }\end{array}$ & $\begin{array}{l}\text { Video-recorded interactions } \\
\text { (h) }\end{array}$ \\
\hline \multirow[t]{7}{*}{ KANYAWARA } & Winza/Wangari & M & $9-11$ & $21-23$ & 105 & 15.2 \\
\hline & Tembo/Tenkere & M & $13-15$ & $25-27$ & 119 & 18.4 \\
\hline & Mango/Michelle & $\mathrm{F}$ & $13-15$ & $25-27$ & 87 & 7.3 \\
\hline & Lily/Leona & $\mathrm{F}$ & $3-5^{\mathrm{a}}$ & $15-17$ & 60 & 7.2 \\
\hline & Thatcher/Tongo & $\mathrm{F}$ & $16-18$ & $28-30$ & 112 & 15 \\
\hline & Gola/Outamba & $\mathrm{F}$ & $48-50^{\mathrm{b}}$ & N/A & 45 & 7.2 \\
\hline & Wallace/Wilma & M & $55-57$ & $67-69$ & 73 & 10.1 \\
\hline \multirow[t]{6}{*}{ TAÏ South } & Mohan/Mbele & $\mathrm{F}$ & $10-12$ & $22-24$ & 150 & 11.2 \\
\hline & Iniesta/Isha & M & N/A & $10-12$ & 91 & 12 \\
\hline & Solibra/Sumatra & M & $15-17$ & $27-29$ & 147 & 14.7 \\
\hline & Jeff/Julia & M & $15^{\mathrm{c}}$ & N/A & 20 & 0.4 \\
\hline & Kayo/Kinshasa & $\mathrm{F}$ & $19-21$ & $31-33$ & 148 & 17.0 \\
\hline & Ithaka/Isha & M & $64-66^{\mathrm{b}}$ & N/A & 41 & 9.5 \\
\hline$\Sigma$ & 13 & $6: 7$ & 11 & 10 & 1198 & 145.2 \\
\hline
\end{tabular}

The last line provides the total sample size for each column (P1/P2: first/second period of data collection)

${ }^{\text {a }}$ P1 not included since infant was too young

b Mothers gave birth to sibling in P2, thus no P2 data available

${ }^{c}$ Deceased on November 1, 2012

sampling utilised as sampling/recording rule (Altmann 1974). This method enabled us to collect data on a variety of additional parameters such as behavioural context and party composition (see Online Resource 1, Table S2), resulting in a total of 4505 behavioural scans.

\section{Video coding procedure}

To establish the behavioural repertoires of mothers and infants used to initiate maternal carries and enable subsequent analyses, a total of 410 high-quality video files of mother-offspring carry initiations (i.e. carries with clear visibility of carry-initiating behaviours) were coded using the program Adobe Premiere Pro CS4 (version 4.2.1.). In addition, we included PDA recordings of five interactions, resulting in a total of 415 interactions. Behavioural definitions were based on established ethograms of the behaviour of two long-term studies of eastern chimpanzees (Goodall 1986; Nishida et al. 1999) and several gesture studies (Call and Tomasello 2007; Hobaiter and Byrne 2011; Roberts et al. 2014a). Based on parameters used in previous work on great ape gesturing (Pika et al. 2003, 2005; Pika and Mitani 2006), a coding scheme was developed. For our purposes, all analysed joint travel events included maternal carries (i.e. involving mother-infant body contact). While coding all agent-initiated carries, we differentiated between carry-initiating behaviours via (1) physical actions, (2) intentionally produced gestures, (3) multi-modal combinations (gesture plus vocalisation) and (4) vocalisations. A physical action was defined as any behaviour that resulted in joint travel through direct manipulation of another's body or the movement of one's own body into a carry position. Carryinitiating actions included, for instance, grabbing, forcibly pulling, lifting or approaching another individual (see Online Resource 1, Table S1). Gestures were defined as directed, mechanically ineffective movements of the body or body postures that elicited ('requested') a voluntary response by the recipient (Pika 2008). In addition, we only included those gestures in our analyses that were accompanied by one or more key characteristics of intentional communication (Bates 1976; Bruner 1981; Pika et al. 2003):

Sensitivity to the attentional state of the recipient The signaller shows signs of being aware of the recipient's state of attention, e.g. by using visual gestures only when the recipient is looking.

Response waiting The signaller pauses at the end of the signal and waits for at least two second for a response while maintaining visual contact.

Apparent satisfaction of signaller The signaller's communication ceases when the apparent goal has been met by the recipient (Hobaiter and Byrne 2014).

Goal persistence The signaller elaborates her signalling when thwarted, e.g. by repeating and exaggerating the signal or by using a different communicative means (Pika et al. 2005; Pika and Mitani 2006).

Gestures were clustered into three signal categories: audible (signals generate a sound while being performed, e.g. SLAP GROUND), tactile (signals include physical contact 
with the recipient, e.g. TOUCHING) and visual (signals generate a mainly graphic component, e.g. RAISE ARM) signals (Pika et al. 2003). To identify carry initiations, the behaviour of both, the signaller and the recipient throughout the interaction, from first initiating action/gesture to start of carry, was taken into account to assess the success of communicative attempts (Smith 1965). Idiosyncratic gestures, which are exclusive for single individuals in the whole community, had been observed at least three times to be included in the analyses (Pika et al. 2003, 2005). Vocalisations, especially those accompanying gestures ('multi-modal signals'), were analysed in terms of their broad categories (Crockford and Boesch 2005; Goodall 1986; Table 2). Finally, for each signal or action case, we coded the following parameters: interaction role of the signaller: two levels, mother, infant; infant age: range 9-69 months; necessity of carry: two levels (low; carry preceded by feeding, playing, resting, relaxed group travel; high: preceded by aggressive behaviours such as chasing and hitting, catching-up with already left party/group, displaying and patrolling); mother's parity: number of offspring reared at least until juvenility (plus present infant), range $1-5$, party composition: three levels (mother with dependent offspring only, adult females only, mixed group). A least 15 per cent of all mother-infant interactions were coded for accuracy by a second observer and tested using the Cohen's kappa coefficient to ensure inter-observer reliability (Altmann 1974). A 'very good' level of agreement was found for gesture type $(\kappa=0.878)$, signal type $(\kappa=0.811)$, signal category $(\kappa=0.843)$ and necessity of carry $(\kappa=0.816)$. The level of agreement for carry initiator (mother/infant) was 'good' $(\kappa=0.799)$.

\section{Statistical analyses}

Since Byrne and colleagues (Genty et al. 2009; Hobaiter and Byrne 2011) had argued that differences in gestural repertoires of captive apes were simply premature assumptions, with repertoires yet to reach asymptote, we plotted the cumulative numbers of observed gesture types over time for all individuals. If an asymptote was reached (i.e. no further gesture types were observed), we concluded that we had observed the individual's full repertoire for the specific communicative function of maternal carries. We measured the relationship between an individual's final repertoire size and the total time that individual had been observed using the Spearman R statistic. For our repertoire analyses, we included only individuals observed for over $60 \mathrm{~h}(N=10$; observation time range $60.25-150 \mathrm{~h}$, mean $\pm \mathrm{SD}=109.3 \pm 32.1 \mathrm{~h}$ ), which have reached the critical asymptote, to make sure that the complete repertoire of these individuals was grasped within the observation time. We compared repertoire sizes of mother and infants using an independent-samples $t$ test after the underlying assumptions were tested (Levene's test for equality of variances).

To enable a better understanding of gestural acquisition, the gestural repertoires of mothers of the two communities of Kanyawara and Taï South were compared. To assess concordance rates of gestural repertoires within dyads, within groups and between groups, we used the Dice coefficient $\left(\mathrm{D}_{c}\right)$, which ranges from 0 to 1 (Dice 1945). A value of 0 means that two individuals have no gesture types in common, while a value of 1 would mean that the two gestural repertoires are identical. Since chimpanzee infants had very limited gestural repertoires in the specific context of carry initiation, we restricted this particular analysis to maternal repertoires only. In addition, we included in the analysis only data of individuals, whose repertoires had reached asymptote. To investigate whether repertoire similarity was larger between mothers of the same community than between mothers of different communities, we used a matrix permutation test (Sokal and Rohlf 1995).

To test to which extent the predictor variables such as infant age, interaction role, carry necessity and mother's parity influenced signal type (action, visual gesture, tactile gesture; response variables), we used generalised linear mixed models (GLMM; Baayen 2008) with a binomial error structure and logit link function. We fitted one model for each of the three response variables. Into this, we included interaction role, infant age, carry necessity and mother's parity as our key test predictors, respectively. Another model was specified for carry initiator as binomial response variable $(0=$ mother initiation, $1=$ infant initiation), but only infant age and parity were specified as key test predictors in this model. Since the average age varied considerably between infants but also within them, we used the method of within-subject centring (van de Pol and Wright 2009). This method allows to test whether the effect of age takes place largely across subjects (crosssectional) or within subjects (longitudinal). Practically, this means that we include two predictors representing age into the model: one representing the average age per infant (from here on called within-infants age) and the other being the difference between the date that the observation was made (from here on called between-infants age) and its average age. Because we assumed that over the course of ontogeny, infants would take a more active role we also included the two two-way interactions between role and the two variables representing infant age into the first three models. To control for confounding effects, we also included party composition, infant sex and study site as further fixed effects. As random effects (intercepts), we included the identity of the mother and the infant into the model. To keep type 1 error rates at the nominal level of $5 \%$, we also included the random slopes components of 
Table 2 Gesture and vocalisation types produced to initiate carries in chimpanzee mother-infant dyads identified in this and other studies on wild groups in Budongo (Hobaiter and Byrne 2011; Roberts et al. 2014a); Gombe (Goodall 1986) and Mahale (Nishida et al. 1999)

\begin{tabular}{|c|c|c|c|c|c|}
\hline Gesture/vocalisation & Definition (this study) & $\begin{array}{l}\text { Used } \\
\text { by }\end{array}$ & Budongo & Gombe & Mahale \\
\hline \multicolumn{6}{|l|}{ Audible } \\
\hline LOUD SCRATCH [LS] & Signaller makes deliberate scratching movements on own body & Mother & $\begin{array}{r}\text { Big loud } \\
\text { scratch }\end{array}$ & Self-scratch & $\begin{array}{c}\text { Scratch self } \\
\text { signalling }\end{array}$ \\
\hline SLAP GROUND [SG] & Signaller hits ground with flat palm of his hand & Mother & $\begin{array}{l}\text { Slap } \\
\text { object }\end{array}$ & Slap ground & Slap branch \\
\hline \multicolumn{6}{|l|}{ Tactile } \\
\hline ARM ON $[\mathrm{AO}]$ & Signaller places palm on recipient's back ( $>2 \mathrm{~s}$ ) & Infant & Hand on & - & - \\
\hline SHaKe BaCK* $[\mathrm{sB}]$ & $\begin{array}{l}\text { Signaller shakes lower back in an upward movement when } \\
\text { recipient is already clinging }\end{array}$ & Mother & - & - & - \\
\hline SCOOP INFANT $[\mathrm{RB}]$ & $\begin{array}{l}\text { Signaller reaches behind himself and gently pushes infant up } \\
\text { onto back with a back ward and upward movement }\end{array}$ & Mother & Scoop & Scoop & $\begin{array}{l}\text { Scoop } \\
\text { infant }\end{array}$ \\
\hline Touch [то] & $\begin{array}{l}\text { Signaller makes short ( }>2 \mathrm{~s} \text { ) contact with recipient using palm } \\
\text { and/or fingers }\end{array}$ & Both & $\begin{array}{l}\text { Touch } \\
\text { inner } \\
\text { hand }\end{array}$ & Touch & Touch \\
\hline DIRECTED PUSH [PU] & $\begin{array}{l}\text { Signaller uses limbs or body to bring recipient in direction of } \\
\text { movement }\end{array}$ & Mother & $\begin{array}{l}\text { Directed } \\
\text { push }\end{array}$ & $\begin{array}{l}\text { Pull towards } \\
\text { hand } \\
\text { leading }\end{array}$ & Push ahead \\
\hline Pull [PL] & Signaller moves recipient's body part towards himself & Both & Pull & Pull & Pull \\
\hline PUT VENTRAL $[\mathrm{PV}]$ & Signaller pushes recipient in ventral region & Mother & - & - & Put ventral \\
\hline \multicolumn{6}{|l|}{ Visual } \\
\hline BACKWARD SWEEP [BS] & $\begin{array}{l}\text { Signaller stretches arm towards behind himself in a short, rapid } \\
\text { movement }\end{array}$ & Mother & $\begin{array}{l}\text { Backward } \\
\text { sweep }\end{array}$ & Climb aboard & - \\
\hline EXTEND LEG [EL] & Signaller extends leg to facilitate climb onto self & Mother & $\begin{array}{l}\text { Present } \\
\text { leg }\end{array}$ & - & $\begin{array}{l}\text { Extend leg } \\
\text { as ladder }\end{array}$ \\
\hline LoOK [LO] & Signaller gazes at recipient (>2 s) & Both & Look & Wait & Look; wait \\
\hline LOWER BACK [LR] & $\begin{array}{l}\text { Signaller, in lateral position to recipient, lowers abdomen } \\
\text { without stopping locomotion }\end{array}$ & Mother & & & \\
\hline $\begin{array}{l}\text { STOP AND LOOK BACK/ } \\
\text { DOWN [LB/LD] }\end{array}$ & $\begin{array}{l}\text { Signaller stops with body orientated in direction of movement } \\
\text { and looks back (or down) at recipient }\end{array}$ & Both & - & - & Look back \\
\hline $\begin{array}{l}\text { PRESENT BACK/ } \\
\text { SHOULDER/VENTER [PB, } \\
\text { PS, PV] }\end{array}$ & Signaller offers back/venter to recipient & Mother & Present & Present & Present \\
\hline REACH [RA] & Signaller extends arm towards recipient & Both & Reach & Extend hand & Extend hand \\
\hline REAR UP* [RU] & $\begin{array}{l}\text { Signaller briefly rises straight up on two feet while positioned } \\
\text { towards recipient }\end{array}$ & Mother & - & - & - \\
\hline $\begin{array}{l}\text { TURN BIPEDAL } * \text { T⿱一土㇒| } \\
\text { Vocalisations }\end{array}$ & Signaller turns towards recipient with short bipedal movement & Mother & - & - & - \\
\hline HOO WHIMPER [HOO] & $\begin{array}{l}\text { Signaller utters a series of soft, low pitch sounds that may } \\
\text { become progressively louder and higher in pitch }\end{array}$ & Infant & - & Whimper & Whimper \\
\hline SOFT GRUNT [SGR] & Signaller utters a soft, barely voiced sound & Mother & - & Soft grunt & Grunt \\
\hline
\end{tabular}

role, within-infants age and their interaction as well as carry necessity within infant identity (Barr et al. 2013; Schielzeth and Forstmeier 2009). We did not include any other random slopes components within mother ID because with a single exception each mother only had a single infant and hence random slopes of these fixed effects within mother ID would be highly redundant. For the other fixed effects, we did not include random slopes because they were most usually constant within mother and infant
ID. We also did not include correlations between random slopes and random intercepts in order to keep model complexity at an acceptable level and because neglected random slopes do not compromise type 1 error rates (Barr et al. 2013). The models were implemented in $R(R$ Core Team 2014) using the function glmer of the package 'Ime4' (Bates et al. 2014). To test the overall significance of our key test predictors (Forstmeier and Schielzeth 2011; Mundry 2014), we compared the full models with the null 
models comprising only the two control predictors with fixed effects as well as all random effects using a likelihood ratio test (Dobson 2002). Prior to running the models, we $z$-transformed between-infants age, withininfants age and parity (Aiken and West 1991; Schielzeth 2010). To control for collinearity, we determined variance inflation factors (VIF; Field 2005; Quinn and Keough 2002) from a model including only the fixed main effects using the function vif of the $\mathrm{R}$ package 'car'. This revealed collinearity to not be an issue (maximum VIF $=1.44$ ). To estimate model stability, we excluded the levels of random effects one at a time, ran the models again and compared the estimates derived with those obtained from the models based on all data. This revealed all models to be at least 'moderately' stable, particularly for those estimates that were not close to zero (for details on model stabilities, see supplementary material in Online Resource 2). Confidence intervals were derived using the function sim of the R package arm (Gelman and Su 2014). Tests of the individual fixed effects were derived using likelihood ratio tests ( $\mathrm{R}$ function dropl with argument 'test' set to 'Chisq'). All statistical analyses were performed using the R-version R.3.1.1 (R Core Team 2014), with a level of significance set to 0.05 .

\section{Results}

During 156 days of observation, we recorded a total of $145.2 \mathrm{~h}$ of video footage on mother-infant interactions (Kanywara: $80.4 \mathrm{~h}, 11.5 \pm 4.7 \mathrm{~h}$ per dyad; Taï South: $64.8 \mathrm{~h}, 10.8 \pm 5.8 \mathrm{~h}$ per dyad; mean \pm S.D.). This method resulted in a total of 415 recordings of mother-infant carry initiations (Kanywara: $N=218 ; 31.1 \pm 13.5$ per dyad; Taï South: $N=197,32.8 \pm 21$ per dyad). The coding of this data set resulted in a total (number of cases) of 442 actions (Kanyawara mothers: $N=178$, infants: $N=20$; Taï mothers: $N=204$, infants: $N=40$ ), 599 gestures (Kanyawara mothers: $N=337$, infants: $N=22$; Taï mothers: $N=228$, infants: $N=12$ ), 51 multi-modal combinations (Kanyawara mothers: $N=2$, infants: $N=28$; Taï mothers: $N=4$, infants: $N=17$ ) and 80 vocalisations (Kanyawara mothers: $N=3$, infants: $N=39$; Taï mothers: $N=6$, infants: $N=32$ ). Hence, across both study sites, chimpanzee mothers produced the bulk of gestures and actions, while infants produced gestures less often to initiate joint travel, but most multi-modal combinations and vocalisations (Fig. 1). Results showed that mothers initiated the majority of observed joint travel events at both study sites (Kanyawara: 153 out of 218 events; $70.2 \%$; Taï: $N=119$ out of 197 events; $60.4 \%$ ). In seven cases could the carry initiator not be clearly determined.

\section{Assessing the influence on sampling size}

To ensure that our assessment of individuals' repertoires had approached and/or reached asymptote, we plotted the cumulative repertoire of gestures over time. The results showed that the cumulative repertoire of mothers approached an asymptote at around the first third of the observation period (see Online Resource 1, Fig. S1). Except for two individuals (MB and JL of Taï South, WA of Kanyawara community) showed the latest observed gesture type of their repertoire within the first two thirds $(67 \%)$ of their total observation time, i.e. within $61.7 \pm 28.8 \mathrm{~h}$ of full observation (mean $\pm \mathrm{SD}$ ). During the follow-up seasons, only two additional gestures were recorded (Taï South in 2013). Concerning the gestural repertoires of these ten chimpanzee mother-infant dyads, there was no correlation between the observed time for each dyad and the final gestural repertoire of each individual (mothers: Spearman's $R=0.494, P=0.147$; infants: Spearman's $R=0.253$, $P=0.48)$. Thus, we concluded to have observed the full gestural repertoires employed by ten out of 13 dyads (i.e. 20 individuals) in our respective context and study periods. Consequently, for the analyses of the within- and betweengroup concordance rates, only data from these individuals were used.

\section{Signal repertoires in carry interactions}

To investigate our first question concerning behaviours that chimpanzees employ to initiate joint travel, we analysed actions, gestures, multi-modal combinations and vocalisations for mothers and infants of each site separately. Concerning gestures types, mothers showed a total of one

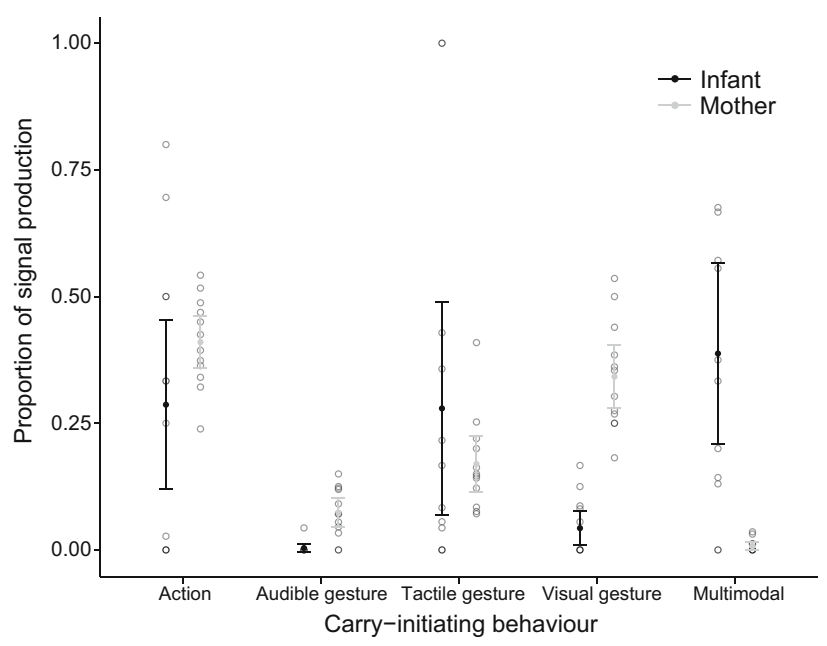

Fig. 1 Proportion of carry-initiating actions, gestures (audible, tactile and visual) and multi-modal combinations produced by infants $(N=12)$ and mothers $(N=12)$, respectively. Error bars depict the mean values and the $95 \%$ confidence intervals 
and two audible, each ten visual, six and five tactile gesture types at Kanyawara and Taï South, respectively (total and mean individual repertoire size Kanyawara: 17; mean $\pm \mathrm{SD}=10 \pm 3.7, \quad N=7 ; \quad$ Taï South: 17 ; $10.2 \pm 4.1, N=5$; Table 3a). Idiosyncratic gestures were performed by three different mothers (i.e. one and two adult females from each Kanyawara and Taï South, each observed more than $112 \mathrm{~h}$ ) and were termed SHAKE BACK, TURN BIPEDAL and REAR UP (see Table 2 for descriptions). Multi-modal combinations in mothers consisted of the vocalisation SOFT HOO with one of the following gestures: PRESENT BACK (visual, observed in OT of Kanyawara) and REACH ARM (visual, observed in MB and IS of Taï South, Table 3b).

Compared with chimpanzee mothers, infants had significantly smaller gestural repertoires $(t=7.993, d f=18$, $P<0.001$; Levene's test for variance equality: $Z=2.424$, $P=0.137$ ), producing one and zero audible, four and two tactile; and three visual gesture types at Kanyawara and Taï South, respectively (total and mean individual repertoire size at Kanyawara: 8 ; mean $\pm \mathrm{SD}=2.3 \pm 1.8$, $N=7$; Tä̈: 5; $2.5 \pm 1.6, N=6$; Table 4a). All gesture types except for one tactile gesture (ARM ON) that was produced by two older infants (WC and OL) at Kanyawara were shared with the mothers (Table 2). Multi-modal combinations in infants consisted of the vocalisation HOO WHIMPER with one of the following gestures: TOUCH (tactile, observed in three infants: MH, TR and WC), LOOK AT (visual, observed in nine infants: IN, IT, KY, MH, OL, SL, TR, WZ), REACH ARM (visual, observed in four infants: IN, $\mathrm{KY}, \mathrm{MH}, \mathrm{TR}$ ) or LOUD SCRATCH (audio-visual, observed in one infant: WC; Table 4b). While there were more visual gesture types and combined forms of gestures and vocalisations observed in older infants (i.e. infants from the second year of life, Table 4b), final gestural repertoire size in both mothers and infants was not significantly correlated with final infant age (mothers: Spearman's $R=-0.037$, $P=0.920, \quad N=10$; infants: Spearman's $R=0.544$, $P=0.104, N=10$ ). Naturally, due to the obvious asymmetry in the carry interaction (Halina et al. 2013) repertoires of chimpanzee infants were more similar to each other than repertoires of mothers. Since the sample sizes of audible gestures and multi-modal signals were comparably low, no inferential statistics has been conducted on this gestural category.

\section{Within- and between-group concordance of mother's carry-initiating gestures}

To address the second question on whether gesture types produced to initiate joint travel are learned during motherinfant exchanges or due to genetic channelling, we calculated the rate of concordances (repertoire similarity) within and between groups by using the Dice coefficient $\left(\mathrm{D}_{c}\right)$. Overall, $\mathrm{D}_{c}$ values were moderate, irrespectively which community the individuals belonged to (overall: $\mathrm{D}_{c}=0.71 \pm 0.1$, mean $\pm \mathrm{SD}$; Kanyawara: $\mathrm{D}_{c}=0.71 \pm$ 0.1; Taï South: $\mathrm{D}_{c}=0.71 \pm 0.05$; see Online Resource 1, Table S3). Comparing the concordance rates of mothers of the same and the other community, we did not find a significant difference between the within-group $\left(\mathrm{D}_{c}=0.71 \pm 0.1\right)$ and the between-group Dice coefficients $\left(\mathrm{D}_{c}=0.71 \pm 0.1\right.$; matrix permutation: $P=0.839$ ).

\section{Factors influencing signal production and carry initiations}

To examine the third question on whether infant age influenced the behaviours used to initiate joint travel, we ran four different models. Overall, the test predictors had a clear impact in all models, i.e. on the occurrence of actions, tactile and visual gestures as well as on the role of joint travel initiator [likelihood ratio tests (LRT) comparing null and the full model for action: $\chi^{2}=23.476, d f=7$, $P=0.001$, tactile gesture: $\chi^{2}=18.968, \quad d f=7, P=$ 0.008 , visual gesture: $\chi^{2}=52.795, d f=7, P<0.001$, carry initiator: $\left.\chi^{2}=24.320, d f=4, P<0.001\right]$.

Concerning carry-initiating actions, we found a significant interaction between role and between-infants age (estimate \pm standard error $=0.756 \pm 0.250, \quad \chi_{1}^{2}=11.668$, $P=0.002$ ), with younger infants and mothers of younger infants soliciting more frequently joint travel via actions than older infants (Fig. 2). None of the other effects reached significance (Table 5a).

For tactile gesturing, we found none of the two interactions (role interacting with both between-infants and within-infants age) to be significant. After removal of these non-significant interactions, we found that chimpanzee mothers were less likely to produce tactile gestures with increasing infant age (within-infants age: $-0.164 \pm 0.089$, $\left.\chi_{1}^{2}=2.824, P=0.093\right)$ and produced them more frequently for less urgent carries (carry necessity: $\left.-0.649 \pm 0.210, \chi_{1}^{2}=9.861, P=0.002\right)$. In addition, individuals of the Kanyawara community produced tactile gestures more often than chimpanzees from the Taï South community (site [Taï South]: $-0.646 \pm 0.233$, $\left.\chi_{1}^{2}=5.479, P=0.019\right)$. None of the other effects reached significance (Table $5 b$ ).

In the visual gesturing model, we also found none of the two interactions to be significant. After removal of these non-significant interactions, the results showed that chimpanzee mothers were more likely to produce visual gestures than infants (role [mother]: 2.380 \pm 0.359 , $\left.\chi_{1}^{2}=46.963, P<0.001\right)$. In dyads involving older infants, mothers had a higher frequency of producing visual 


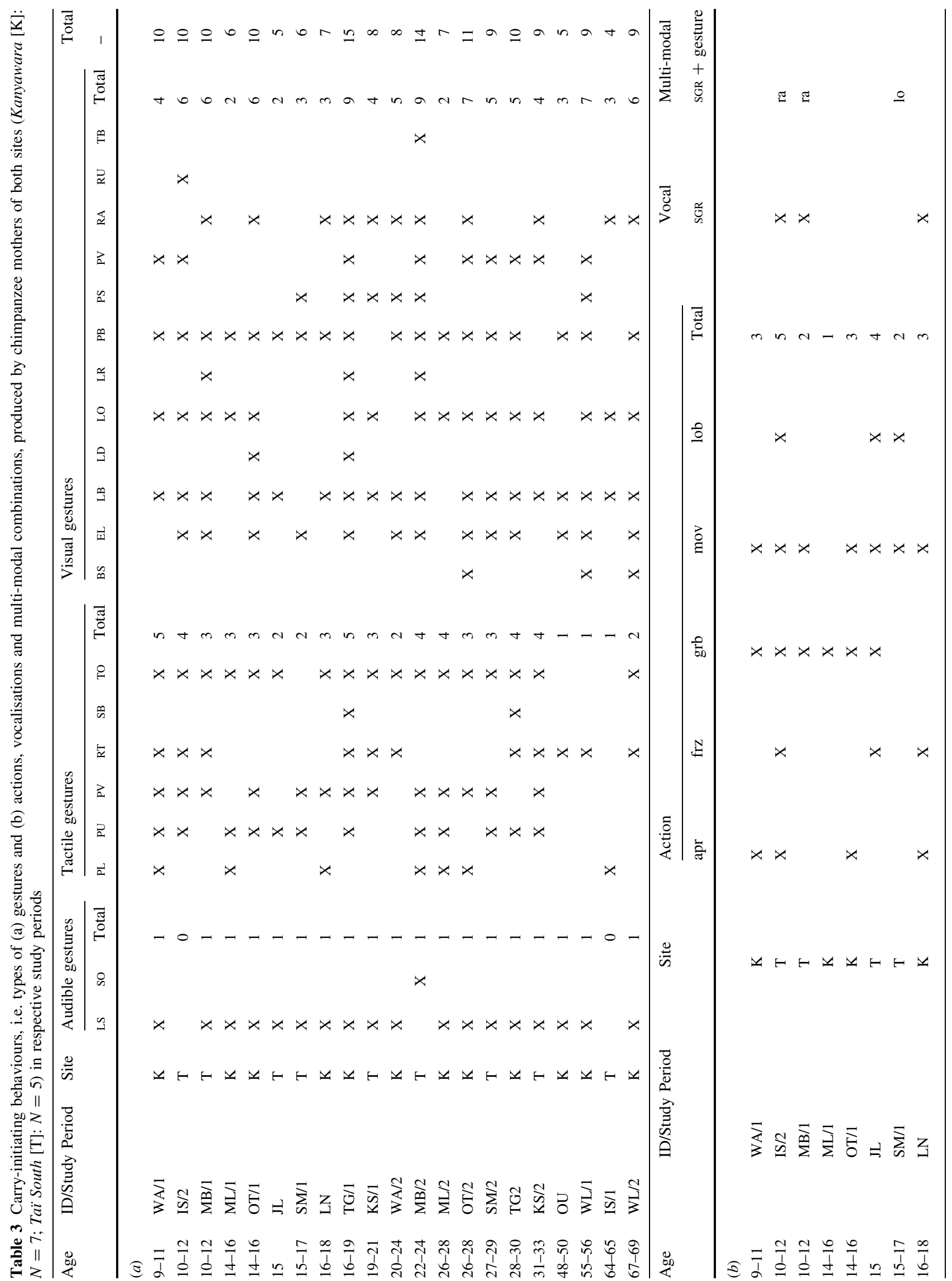




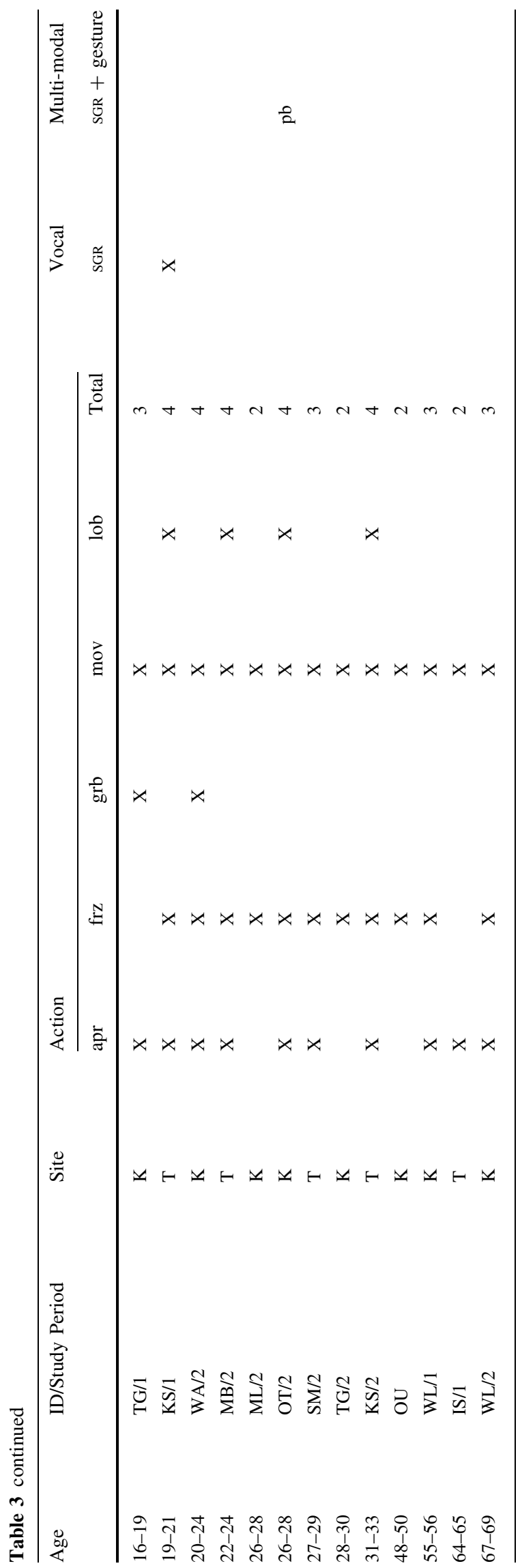

gestures than dyads involving younger infants (betweeninfants age: $0.182 \pm 0.090, \quad \chi_{1}^{2}=2.973, \quad P=0.085$, Fig. 3). In addition, visual gestures were produced more frequently when carries were more necessary (carry necessity: $0.436 \pm 0.163, \chi_{1}^{2}=5.785, P=0.016$, Fig. 4). None of the other effects in the visual gesture model reached significance (Table 5c).

In the fourth model, we examined which factors influenced whether mothers or infants initiated carries for joint travel. After removal of the non-significant interactions, we found a strong effect of infant age: with increasing age, infants initiated more carries (within-infants age: $0.547 \pm 0.242, \quad \chi_{1}^{2}=3.297, P=0.069$; between-infants age: $\left.0.779 \pm 0.163, \chi_{1}^{2}=16.235, P<0.001\right)$. In addition, in dyads with mothers of higher parity, mothers were less likely to initiate carries $\left(0.651 \pm 0.148, \chi_{1}^{2}=11.601\right.$, $P<0.001)$. None of the other effects reached significance (Table 5d).

\section{Discussion}

The main aim of the present study was to gain a better understanding of the complexity and variability of communicative exchanges in chimpanzee mother-infant dyads in natural environments and to shed light on gestural acquisition. Since previous studies on gestural variability have emphasised the importance of long-term observations to reliably assess repertoire size, we observed the communicative behaviour of mother-infant dyads of two chimpanzee communities during two field periods in two consecutive years for more than 150 days, and examined the cumulative frequency of gesture type. The results showed that the rate of adding new gestures to the repertoires of our focal animals of the Kanyawara and Taï South community in the single context of joint travel appeared close to asymptote. Further observations are thus unlikely to contribute many additional gesture types.

We addressed the following three questions: First, which behaviours do chimpanzees employ to initiate joint travel? Second, are gesture types produced to initiate joint travel due to learning or are they the result of genetic channelling? Third, do chimpanzee mothers adjust their behaviour to the developmental stage of their infants, and how does infant age influence signal production in both mothers and infants?

Overall, we found striking differences between mothers and infants concerning the signal frequency and modality employed to initiate joint travel. While mothers were the main initiators of joint travel and mainly relied on gestures to do so, infants solicited joint travel frequently via actions and vocalisations. Gestural repertoires differed considerably between mothers living in the same 
Table 4 Carry-initiating behaviours, i.e. types of (a) gestures and (b) actions, vocalisations and multi-modal combinations, produced by chimpanzee infants of both sites (Kanyawara $[\mathrm{K}]: N=7$; Taï South $[\mathrm{T}]: N=6$ ) in respective study periods

\begin{tabular}{|c|c|c|c|c|c|c|c|c|c|c|c|c|c|c|}
\hline \multirow[t]{2}{*}{ Age } & \multirow[t]{2}{*}{ ID/study period } & \multirow[t]{2}{*}{ Site } & \multicolumn{2}{|c|}{ Audible gestures } & \multicolumn{5}{|c|}{ Tactile gestures } & \multicolumn{4}{|c|}{ Visual gestures } & \multirow{2}{*}{$\begin{array}{l}\text { Total } \\
-\end{array}$} \\
\hline & & & $\mathrm{SC}$ & Total & $\mathrm{AO}$ & то & PL & PU & Total & LO & LB & RA & Total & \\
\hline
\end{tabular}

\begin{tabular}{|c|c|c|c|c|c|c|c|c|c|c|c|c|c|c|}
\hline \multicolumn{15}{|l|}{ (a) } \\
\hline 9-11 & $\mathrm{WZ} / 1$ & $\mathrm{~K}$ & & 0 & & & $X$ & & 0 & $\mathrm{X}$ & & $X$ & 2 & 2 \\
\hline $10-12$ & IN & $\mathrm{T}$ & & 0 & & $X$ & & & 1 & $\mathrm{X}$ & & $X$ & 2 & 3 \\
\hline $10-12$ & $\mathrm{MH} / 1$ & $\mathrm{~T}$ & & 0 & & $X$ & & & 1 & & & $X$ & 1 & 2 \\
\hline $14-15$ & $\mathrm{MM} / 1$ & $\mathrm{~K}$ & & 0 & & $X$ & & & 1 & & & & 0 & 1 \\
\hline $14-16$ & $\mathrm{OB} / 1$ & $\mathrm{~K}$ & & 0 & & & & & 0 & & & & 0 & 0 \\
\hline 15 & $\mathrm{JF}$ & $\mathrm{T}$ & & 0 & & & & & 0 & & & & 0 & 0 \\
\hline $15-17$ & $\mathrm{SL} / 1$ & $\mathrm{~T}$ & & 0 & & $X$ & & & 1 & & & & 0 & 1 \\
\hline $16-18$ & LL & $\mathrm{K}$ & & 0 & & $\mathrm{X}$ & & & 1 & & & & 0 & 1 \\
\hline 16-19 & $\mathrm{TR} / 1$ & $\mathrm{~K}$ & $X$ & 1 & & & & & 0 & & $X$ & $X$ & 2 & 3 \\
\hline 19-21 & KY/1 & $\mathrm{T}$ & & 0 & & $X$ & & & 1 & & & & 0 & 1 \\
\hline $20-24$ & $\mathrm{WZ} / 2$ & $\mathrm{~K}$ & & 0 & & & & & 0 & & & & 0 & 0 \\
\hline $22-24$ & $\mathrm{MH} / 2$ & $\mathrm{~T}$ & & 0 & & $\mathrm{X}$ & & & 1 & $X$ & $X$ & $X$ & 3 & 4 \\
\hline $26-28$ & $\mathrm{MM} / 2$ & $\mathrm{~K}$ & & 0 & & & & & 0 & & & & 0 & 0 \\
\hline $26-28$ & $\mathrm{OB} / 2$ & $\mathrm{~K}$ & & 0 & & & & & 0 & & & & 0 & 0 \\
\hline $27-29$ & $\mathrm{SL} / 2$ & $\mathrm{~T}$ & & 0 & $\mathrm{X}$ & $\mathrm{X}$ & & & 2 & $\mathrm{X}$ & & & 1 & 3 \\
\hline $28-30$ & $\mathrm{TR} / 2$ & $\mathrm{~K}$ & & 0 & & $X$ & & & 1 & & & $X$ & 1 & 2 \\
\hline $31-33$ & $\mathrm{KY} / 2$ & $\mathrm{~T}$ & & 0 & & & & & 0 & $\mathrm{X}$ & $X$ & $X$ & 3 & 3 \\
\hline $48-50$ & $\mathrm{OL}$ & $\mathrm{K}$ & & 0 & $X$ & & & $X$ & 2 & $\mathrm{X}$ & & & 1 & 3 \\
\hline $55-56$ & $\mathrm{WC} / 1$ & $\mathrm{~K}$ & & 0 & $\mathrm{X}$ & $X$ & & & 2 & $X$ & & & 1 & 3 \\
\hline $64-65$ & IT & $\mathrm{T}$ & & 0 & & & & & 0 & $\mathrm{X}$ & & & 1 & 1 \\
\hline $67-69$ & $\mathrm{WC} / 2$ & $\mathrm{~K}$ & $X$ & 1 & $X$ & $X$ & $X$ & & 3 & $\mathrm{X}$ & & & 1 & 5 \\
\hline \multirow[t]{2}{*}{ Age } & \multirow[t]{2}{*}{ ID/Study period } & & \multirow[t]{2}{*}{ Site } & \multicolumn{7}{|c|}{ Action } & \multirow{2}{*}{\multicolumn{2}{|c|}{$\begin{array}{l}\text { Vocal } \\
\text { whi }\end{array}$}} & \multirow{2}{*}{\multicolumn{2}{|c|}{$\begin{array}{l}\text { Multi-modal } \\
\text { whi + gesture }\end{array}$}} \\
\hline & & & & apr & frz & grb & & hon & & Total & & & & \\
\hline \multicolumn{15}{|l|}{ (b) } \\
\hline $9-11$ & $\mathrm{WZ} / 1$ & & $\mathrm{~K}$ & $\mathrm{X}$ & & & & $\mathrm{X}$ & & 2 & \multicolumn{2}{|c|}{$\mathrm{X}$} & \multicolumn{2}{|c|}{ lo } \\
\hline $10-12$ & IN & & $\mathrm{T}$ & $\mathrm{X}$ & & & & $\mathrm{X}$ & & 2 & \multicolumn{2}{|c|}{$\mathrm{X}$} & \multicolumn{2}{|c|}{ lo, ra } \\
\hline $10-12$ & $\mathrm{MH} / 1$ & & $\mathrm{~T}$ & $\mathrm{X}$ & & & & $\mathrm{X}$ & & 2 & & & & \\
\hline $14-15$ & MM/1 & & K & & & & & & & 0 & \multicolumn{4}{|c|}{$\mathrm{X}$} \\
\hline $14-16$ & $\mathrm{OB} / 1$ & & $\mathrm{~K}$ & $\mathrm{X}$ & & & & $\mathrm{X}$ & & 2 & & & & \\
\hline 15 & $\mathrm{JF}$ & & $\mathrm{T}$ & $\mathrm{X}$ & & & & & & 1 & \multicolumn{4}{|c|}{$\mathrm{X}$} \\
\hline $15-17$ & $\mathrm{SL} / 1$ & & $\mathrm{~T}$ & $\mathrm{X}$ & & & & & & 1 & & & & \\
\hline $16-18$ & LL & & $\mathrm{K}$ & $\mathrm{X}$ & & & & & & 1 & \multicolumn{4}{|c|}{$\mathrm{X}$} \\
\hline $16-19$ & $\mathrm{TR} / 1$ & & $\mathrm{~K}$ & $\mathrm{X}$ & $\mathrm{X}$ & & & $\mathrm{X}$ & & 3 & $\mathrm{X}$ & & \multicolumn{2}{|c|}{ lo } \\
\hline $19-21$ & $\mathrm{KY} / 1$ & & $\mathrm{~T}$ & $\mathrm{X}$ & $\mathrm{X}$ & & & $\mathrm{X}$ & & 3 & \multicolumn{2}{|c|}{$\mathrm{X}$} & & \\
\hline $20-24$ & $\mathrm{WZ} / 2$ & & $\mathrm{~K}$ & $\mathrm{X}$ & & & & $\mathrm{X}$ & & 2 & \multicolumn{2}{|c|}{$\mathrm{X}$} & & \\
\hline $22-24$ & $\mathrm{MH} / 2$ & & $\mathrm{~T}$ & $\mathrm{X}$ & & & & $\mathrm{X}$ & & 2 & \multicolumn{2}{|c|}{$\mathrm{X}$} & & , ra, to \\
\hline $26-28$ & $\mathrm{MM} / 2$ & & $\mathrm{~K}$ & $\mathrm{X}$ & & & & & & 1 & $\mathrm{X}$ & & & \\
\hline $26-28$ & $\mathrm{OB} / 2$ & & $\mathrm{~K}$ & $\mathrm{X}$ & $\mathrm{X}$ & & & $\mathrm{X}$ & & 3 & $\mathrm{X}$ & & & \\
\hline $27-29$ & $\mathrm{SL} / 2$ & & $\mathrm{~T}$ & $\mathrm{X}$ & $\mathrm{X}$ & $\mathrm{X}$ & & $\mathrm{X}$ & & 4 & $\mathrm{X}$ & & lo & \\
\hline $28-30$ & $\mathrm{TR} / 2$ & & $\mathrm{~K}$ & $\mathrm{X}$ & & & & $\mathrm{X}$ & & 2 & $\mathrm{X}$ & & & , ra \\
\hline $31-33$ & $\mathrm{KY} / 2$ & & $\mathrm{~T}$ & $X$ & $X$ & $X$ & & $X$ & & 4 & X & & & $\mathrm{ra}$ \\
\hline $48-50$ & $\mathrm{OL}$ & & $\mathrm{K}$ & & & & & & & 0 & X & & lo & \\
\hline $55-56$ & $\mathrm{WC} / 1$ & & $\mathrm{~K}$ & $X$ & & & & $X$ & & 2 & X & & lo & \\
\hline $64-65$ & IT & & $\mathrm{T}$ & $X$ & & & & & & 1 & X & & lo & \\
\hline $67-69$ & $\mathrm{WC} / 2$ & & $\mathrm{~K}$ & & & & & & & 0 & X & & & , sc, to \\
\hline
\end{tabular}




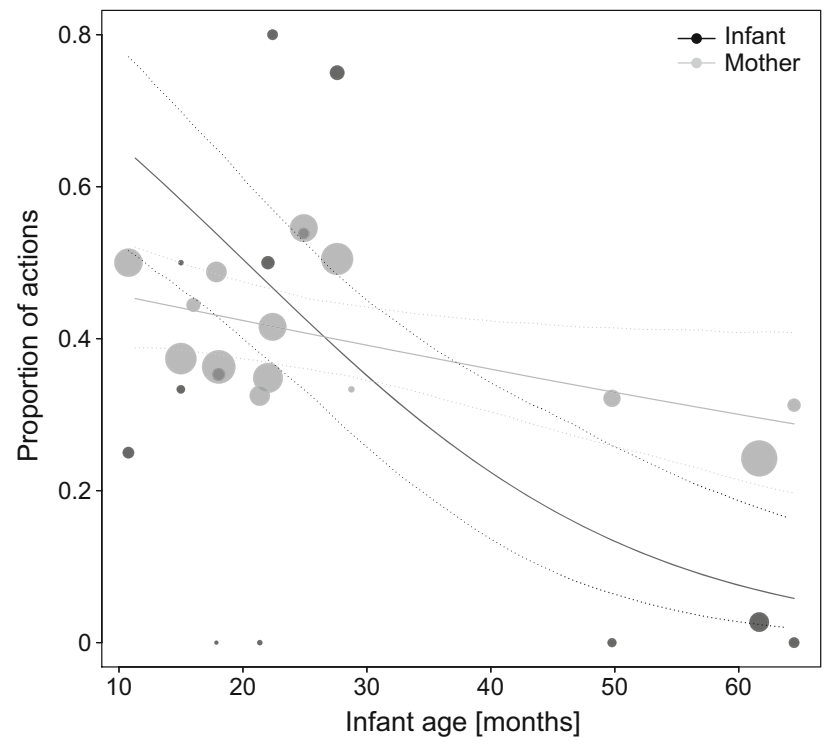

Fig. 2 Proportion of actions employed to initiate joint travel as a function of dyadic role and infant age. Depicted are proportions, separately for each mother and infant of a dyad against mean infant age. The area of the dots corresponds to the sample size per individual (range 1-132); the solid and dashed lines represent the fitted model and confidence intervals based on all covariates and factors centred to a mean of zero

community but also between mothers living in different communities. We observed three cases of idiosyncratic gesture performance employed by three different mothers, with one case performed across both study periods. No evidence of community-specific gesture performance was found. Furthermore, the results indicated that infant age and necessity of the carry had a crucial impact on signal production. In the following paragraphs, we will discuss each of our research question and the related findings in detail.

Chimpanzee mothers and infants differed considerably in the behavioural modalities used to initiate joint travel, but also in their communicative tool set, i.e. the variety of actions, gestures and multi-modal combinations employed. This result is in line with our expectations since the asymmetry of the carry interaction predicts 'one-way' production of distinct actions and gesture types such as for instance lift on back, BACKWARD SWEEP and ARM ON (Halina et al. 2013). However, chimpanzee mothers also initiated the majority of all carry instances and showed a much higher frequency and variety of gesture types produced, with maternal repertoires being generally much larger than infant repertoires. These results are in some contrast to a similar study on bonobo gesturing in captivity, with infants actively soliciting joint travel more often and producing a higher variety of gestures (Halina et al. 2013). There are two different explanations: First, differences between the two studies might represent differences in communication styles or the sensitivity to 'cultural variation' of bonobos and chimpanzees (Pollick and De Waal 2007). Since the two Pan species seem to differ extensively concerning the risks of infanticide, male harassment and resulting coalition styles (e.g. Boesch 1991; Mitani et al. 2000; Surbeck et al. 2011; van Schaik 1996), strong mother-infant associations and relationships in chimpanzees may have been selected for. This in turn may then have triggered a higher degree of protectiveness and modification of the communicative tool kit. However, we can neither verify nor refute this explanation since to date no quantitative comparisons of mother-infant communication in bonobos and chimpanzees are available. A second and more parsimonious explanation therefore is that differences between the two studies might simply represent different sampling methods applied and diverging ecological environments (i.e. captive versus natural environments). Both bonobos and chimpanzees have to cope in the wild with relatively long travel distances between feeding patches (Furuichi et al. 2008; Pontzer and Wrangham 2004), encountering other group members on a regular basis. Consequently, the maternal style of protectiveness described in captivity-associated with contact-making, approaching and restraining the infant (De Lathouwers and Van Elsacker 2004) — may play an important role over an even more extended time period in natural environments. Intriguingly, our results showed that mothers with higher parity were less likely to initiate joint travel. It seems possible that multiparous mothers, i.e. those that live in the community for several years, act less cautious because they have more experience in evaluating and assessing possible dangers and risks due to previously reared offspring.

An additional important difference between mother and infant signalling concerned the use of the communicative modality: Mothers mainly produced visual gestures, while infants preferred to initiate joint travel via vocalisations (i.e. HOO WHIMPER) or multi-modal combinations (i.e. HOO WHIMPER and LOOK; HOO WHIMPER and REACH). Especially in older infants from the age of 2 years, vocalisations were frequently used in intentional ways in combination with (mainly visual) gestures. Thus, similarly to some alarm calls of chimpanzees (Schel et al. 2013), whimpering might develop into an intentional signal with the goal of inducing the mother's interaction through understanding of the signal meaning through its social effect (Plooij 1978). Our study thus adds a new facet to developmental processes in vocal and gestural signalling (Pika et al. 2003; Seyfarth and Cheney 1997) by providing the first evidence that at least in some contexts, a developmental shift from merely vocal to mainly gestural signalling takes place. Furthermore, WHIMPERING in chimpanzee infants seems to gain its communicative intentional function in concert with gestures that function to re-establish physical contact with the 
Table 5 Factors influencing (a) action production, (b) tactile gesture production, (c) visual gesture production and (d) initiator of carry initiation in mother-infant dyad

\begin{tabular}{|c|c|c|c|c|c|c|c|}
\hline & Estimate & se & $\chi^{2}$ & $P$ & LRT $\chi^{2}$ & $d f$ & $P$ \\
\hline \multicolumn{8}{|l|}{ (a) Action } \\
\hline Intercept & -0.758 & 0.318 & (a) & (a) & 23.476 & 7 & 0.001 \\
\hline Role (mother) & 0.217 & 0.207 & (a) & (a) & & & \\
\hline Within-infants age & -0.185 & 0.201 & (a) & (a) & & & \\
\hline Between-infants age & -0.988 & 0.248 & (a) & (a) & & & \\
\hline Carry necessity & 0.009 & 0.154 & 0.003 & 0.953 & & & \\
\hline Parity & 0.007 & 0.096 & 0.005 & 0.942 & & & \\
\hline Party (females) & -0.042 & 0.24 & 0.031 & 0.861 & & & \\
\hline Party (mixed) & -0.127 & 0.237 & 0.287 & 0.592 & & & \\
\hline Infant sex (male) & 0.019 & 0.185 & 0.010 & 0.919 & & & \\
\hline Site (Taï) & 0.407 & 0.195 & 3.705 & 0.054 & & & \\
\hline Role: within-infants age & 0.215 & 0.223 & 0.924 & 0.336 & & & \\
\hline Role: between-infants age & 0.756 & 0.25 & 11.668 & 0.001 & & & \\
\hline \multicolumn{8}{|l|}{ (b) Tactile gesture } \\
\hline Intercept & -1.437 & 0.383 & (a) & (a) & 18.968 & 7 & 0.008 \\
\hline Role (mother) & 0.065 & 0.258 & 0.064 & 0.800 & & & \\
\hline Within-infants age & -0.164 & 0.089 & 2.824 & 0.093 & & & \\
\hline Between-infants age & 0.049 & 0.136 & 0.139 & 0.709 & & & \\
\hline Carry necessity & -0.649 & 0.210 & 9.861 & 0.002 & & & \\
\hline Parity & -0.019 & 0.11 & 0.030 & 0.863 & & & \\
\hline Party (females) & 0.274 & 0.331 & 0.683 & 0.409 & & & \\
\hline Party (mixed) & 0.149 & 0.299 & 0.253 & 0.615 & & & \\
\hline Infant sex (male) & 0.006 & 0.218 & 0.001 & 0.979 & & & \\
\hline Site (Taï) & -0.646 & 0.233 & 5.479 & 0.019 & & & \\
\hline \multicolumn{8}{|l|}{ (c) Visual gesture } \\
\hline Intercept & -3.134 & 0.428 & (a) & (a) & 52.795 & 7 & $<0.001$ \\
\hline Role (mother) & 2.380 & 0.359 & 46.963 & $<0.001$ & & & \\
\hline Within-infants age & -0.006 & 0.106 & 0.003 & 0.957 & & & \\
\hline Between-infants age & 0.182 & 0.090 & 2.973 & 0.085 & & & \\
\hline Carry necessity & 0.436 & 0.163 & 5.785 & 0.016 & & & \\
\hline Parity & 0.109 & 0.082 & 1.760 & 0.185 & & & \\
\hline Party (females) & -0.148 & 0.252 & 0.343 & 0.558 & & & \\
\hline Party (mixed) & 0.122 & 0.245 & 0.250 & 0.617 & & & \\
\hline Infant sex (male) & -0.069 & 0.16 & 0.187 & 0.665 & & & \\
\hline Site (Taï) & 0.029 & 0.168 & 0.029 & 0.864 & & & \\
\hline \multicolumn{8}{|l|}{ (d) Infant carry initiation } \\
\hline Intercept & -1.944 & 0.476 & (a) & (a) & 24.320 & 4 & $<0.001$ \\
\hline Within-infants age & 0.547 & 0.242 & 3.297 & 0.069 & & & \\
\hline Between-infants age & 0.779 & 0.163 & 16.235 & $<0.001$ & & & \\
\hline Carry necessity & 0.004 & 0.286 & 0.000 & 0.990 & & & \\
\hline Parity & 0.651 & 0.148 & 11.601 & 0.001 & & & \\
\hline Party (females) & 0.912 & 0.482 & 3.836 & 0.050 & & & \\
\hline Party (mixed) & 0.768 & 0.470 & 2.807 & 0.094 & & & \\
\hline Infant sex (male) & 0.027 & 0.297 & 0.008 & 0.928 & & & \\
\hline Site (Taï) & 0.468 & 0.286 & 1.923 & 0.165 & & & \\
\hline
\end{tabular}

Bold values indicate $P<0.05$

(a) Significance test not indicated because it has no meaningful interpretation mother. Similarly, Goodall (1967) described several clearcut signals produced by chimpanzee infants that served to re-establish physical contact with the mother (e.g. REACH
ARM, accompanied by pout face and HOO WHIMPER). Hence, when studying the development of communicative skills in chimpanzees and probably also other great ape species, it 


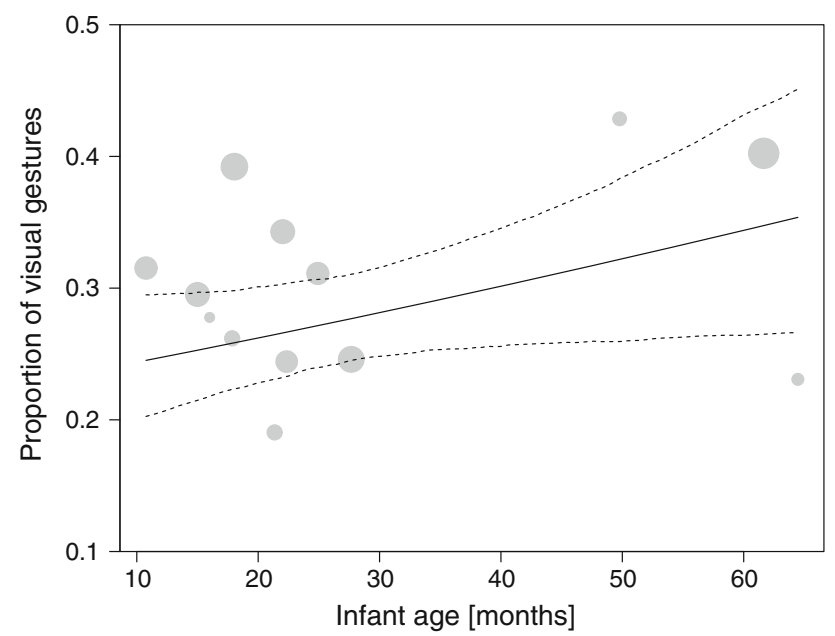

Fig. 3 Proportion of visual gestures employed to initiate joint travel as a function of infant age. Depicted are proportions, separately for each dyad against the respective mean infant age. The area of the dots corresponds to the signal sample size per mother-infant dyad (range 20-171); the solid and dashed line(s) represent the fitted model and confidence intervals based on all covariates and factors centred to a mean of zero

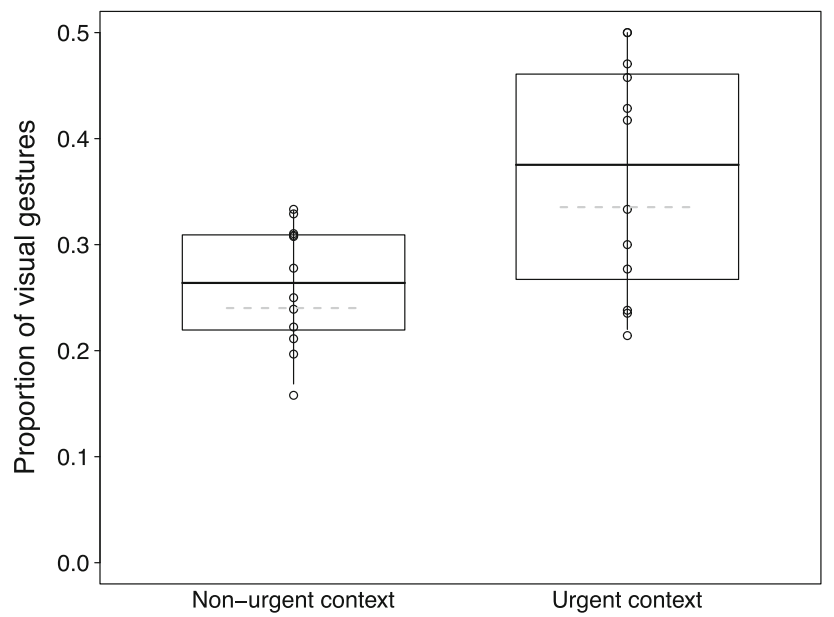

Fig. 4 Proportion of visual gestures employed to initiate joint travel as a function of carry necessity. The dashed lines represent the fitted model (conditional on all covariates and factors centred to a mean of zero)

seems absolutely mandatory to make use of a multimodal approach to communicative complexity (e.g. Slocombe et al. 2011).

Although it has been shown numerous times that great apes use gestures in intentional and flexible ways and are able to acquire novel gesture types (Pika 2015), it remains controversial how great ape repertoires are acquired. In the most predominant hypothesis, gestures are learned via OR (Tomasello et al. 1994), while another hypothesis postulates that gestural production is innate, leaving no room for modification of form over time but including flexible use across contexts (Genty et al. 2009; Hobaiter and Byrne 2011). To contribute to this debate, we carried out the first systematic comparison of communicative exchanges in mother-infant dyads living in two different chimpanzee communities. We paid particular attention to the main criticisms raised by Byrne and colleagues (Genty et al. 2009; Hobaiter and Byrne 2011) on captive studies (e.g. the definition of idiosyncracy and shortage of observational periods). Our results showed only moderate levels of concordance rates between the individual gestural repertoires of mothers living in the same community but also between subspecies and communities. We did not find any evidence for subspecies/community-specific gesture production, but observed three distinct gesture types, which were produced by single mothers only (REAR UP, TURN BIPEDAL and SHAKE BACK) across both study periods. The gestural repertoires of these three females had approached an asymptote within the first observation period. A detailed review of the ethograms of two long-term studies of chimpanzee behaviour (Goodall 1986; Nishida et al. 1999) and several gesture studies (Call and Tomasello 2007; Hobaiter and Byrne 2011; Roberts et al. 2014a) did not produce any comparable behaviours in any other chimpanzee community or group. There are three possible explanations: First, gestural production can be explained by genetic channelling only (Genty et al. 2009; Hobaiter and Byrne 2011). If this hypothesis were true, then we would have expected to find high levels of gestural concordances within and between groups and no evidence for idiosyncracy. This prediction does not accord with our observations. Second, gestural production is due to genetic channelling with gestural variability between groups representing genetic dissimilarity of two subspecies. If this hypothesis were true, then we would have expected to find high degrees of gestural concordances within groups but not between groups, which also does not accord with our observation. However, since evidence of high degrees of gestural concordances within single communities does not enable to differentiate between the processes of genetic channelling or social learning (Bandura 1986), investigations of gestural production of several communities of eastern and/or western African chimpanzees would have been compulsory. Nevertheless, although systematic investigations of gestural signals have so far mainly been focusing on wild communities of Eastern African chimpanzees (Goodall 1986; Hobaiter and Byrne 2011; Nishida et al. 1999; Roberts et al. 2014a), the majority of studies on chimpanzee behaviour provide evidence for considerable inter-site variability rather than differences between subspecies including communicative signalling (e.g. Boesch et al. 1994; Whiten et al. 1999). Third, gestures produced during mother-infant interactions are due to learning. Consistent with this hypothesis is the finding of gestural 
variability, with moderate levels of concordances in the class of mothers within and between groups. Furthermore, we found clear evidence for the production of three idiosyncratic gesture types produced by three different females, which, to our knowledge, have not been described by other researchers. Since we applied even more conservative criteria than previous studies producing similar findings concerning the acquisition of gestures in great apes (Call and Tomasello 2007; Halina et al. 2013; Roberts et al. 2014a), we conclude that indeed learning plays a crucial role in gestural acquisition. However, to address the question which gesture types are more prone to be acquired (e.g. Bard et al. 2014) and which exact details are picked up upon, new methodological tools and fine-grained analyses are crucial (Perlman et al. 2012). Furthermore, we postulate a revised theory of gestural acquisition, 'social negotiation', because the theory of OR (a) is in our view not a completely satisfactory explanation and (b) has led to several misconceptions. First, since it postulates that a physically effective sequence of actions is 'ritualised' into a communicative signal (Tomasello et al. 1994), several researchers have tried rather unsuccessfully to identify these action sequences (Genty et al. 2009; Hobaiter and Byrne 2011). Second, it is widely assumed that gestures acquired via OR cannot be generalised across dyads, resulting in one-way gestures, idiosyncratic repertoires (Genty et al. 2009; Halina et al. 2013; Tanner et al. 2006) and thus no shared meaning within communities. This is beside the evidence that chimpanzees and bonobos (a) are able to use referential gestures and ideograms across contexts and experimenter (e.g. Gardner and Gardner 1991; Savage-Rumbaugh et al. 1986), (b) utilise some groupspecific gestures which carry different meanings across groups (for an overview see Pika et al. 2005) and (c) understand the goals and intention of others as well as thirdparty relationships (Call and Tomasello 2008; Mitani et al. 2000). They thus clearly possess the cognitive abilities to also generalise established communicative value and meaning of gestures across dyads in their natural communication with conspecifics (for evidence concerning continuity of gestural repertoire across time and interaction partners in gorillas, see Tanner 1993).

The redefined theory of social negotiation (sensu Plooij 1978; Wittgenstein 1953) thus proposes that the creation of gestures does not begin with shaping and shortening of a functional action sequence, but an exchange of social behaviours resulting in a shared understanding that certain behaviours (a) can be used communicatively, (b) carry distinct meaning linked to particular social contexts and (c) are produced to achieve distinct goals. This knowledge can be generalised across dyads to enable the most efficient and least costly communication transfer but is also open to subsequent adaptation (e.g. a gesture might first be used to initiate play but later to impress a possible rival). In line with this theory, Bard et al. (2014) recently proposed that most gestures emerge from meaningful social interactions through inter-subjective processes, vary according to the context (Fogel and Thelen 1987) and may rely on 'continued communicative validation'. While the form of gestures is indeed naturally constrained by anatomical features and movement restrictions of a given species (sensu Hobaiter and Byrne 2011), but also the communicative scenario (e.g. short-distance communication versus longterm communication, interaction partner), social context (Wittgenstein 1953) and recipient-affordances (attentional state, location, posture and distance to recipient; Pika 2014), the outcome is 'mutually shaped' (King 2004) or in our words 'social negotiated' by interactants in real time. The resulting gestural output is a manifold variation concerning manner, size, scope, strength, location and orientation of gesture. For instance, although researchers concordantly embrace light and brief (under $2 \mathrm{~s}$ ) contact of the palm and/or fingers of signallers on the body of the recipient under the single umbrella term тоUсH, each gestural performance of a TOUCH gesture by a given signaller is a highly variable online adjustment (Perlman et al. 2012). Additional, in-depth studies of ape gestural production are needed to investigate the form of gestures in relation to developmental phase, context and interaction partner.

Concerning developmental trends and the question whether mothers adjusted their gestural communication to the developmental stage of their infants, we found that visual gestures were employed more frequently with increasing infant age, while the production of tactile gestures decreased. In addition, carry-initiating actions were produced more frequently by dyads with younger infants and decreased considerably with progressing development. Moreover, older infants initiated more carries than younger infants. These findings are in line with our expectations since with increasing age, chimpanzee infants quite naturally increase the distance to their mothers and become intentional agents, who manipulate the attentional and maybe also the mental states of their conspecifics (Pika and Mitani 2006; Plooij 1979; Tomasello et al. 2003). Our findings thus support the notion of Goodall (1967), who suggested that chimpanzees' communicative development may rely heavily on the infant leaving the 'security range' of the mother and entering the complex social environment. As physical distance between mothers and their maturing infants increases, visual gestural communication, in addition to vocalisations, becomes the most crucial communicative modality for mother-infant coordination (Bard et al. 2005; van Lawick-Goodall 1967). With regard to behaviours that were used to initiate joint travel in mother-infant dyads of different study sites, we found no group-specific patterns of carry initiations. Observed 
patterns at both sites were consistent with anecdotal observations concerning gesture types (e.g. EXTEND LEG, LOOK BACK, PRESENT BACK) and use of multimodal signals (e.g. HOO WHIMPER + REACH ARM) reported from Gombe (Goodall 1986; Plooij 1978; van Lawick-Goodall 1967). However, since we systematically addressed the communicative function of carry initiations, our study revealed many more gestures types and thus enabled a more detailed understanding of the variability of carry-initiating actions, gestures and vocalisations employed for this single communicative function.

Surprisingly, our results revealed that visual, but not tactile, gestures were frequently produced in 'evolutionarily urgent' situations, i.e. contexts that underlie strong selection pressure, such as catching-up with an already left party, aggression and group travel. Our findings thus question the hypothesis of Tomasello and Zuberbühler (2002), proposing that primate gestural communication shows more flexibility than primate vocal communication due to gestures being employed in less evolutionary urgent contexts. Quantitative comparisons of the frequency of vocal and gestural production with respect to context urgency have, however, not been carried out. The only exemption is the study by Hobaiter and Byrne (2012), which showed that male chimpanzees preferred to use gestures rather than vocalisations in the evolutionary urgent context of consortship. Gestural communication might therefore outcompete vocal signalling in those contexts when the risk of alerting other group members (e.g. consortship), members of other communities (e.g. patrol) or possible predators is relatively high (however, see Crockford et al. 2012 for usage of soft calls). The employment of visual gestures by mothers might be an adaptive strategy to signal efficiently when a carry would be rather urgent, e.g. when potentially dangerous males arrive or when the party has already left. Contrarily, in nonurgent preceding situations such as feeding via travelling from tree to tree, it might be less crucial for a mother to actively gesture her intention to leave, since her body is indicating the main travel direction and the infant can decide whether to simply follow by himself or whether to climb aboard (Nishida et al. 1999).

In sum, the present study has shown that chimpanzees employ a variety of different behaviours to initiate motherinfant joint travel, with a developmental shift from mainly vocal to gestural signalling and adjustment of mothers to the developmental stage of infants. Applying a windows approach onto communicatory signalling can therefore crucially aid in gaining an in-depth understanding of the communicative tool kit of a given species. Furthermore, by making the first step into the crucial direction of systematic quantitative comparisons of communicative signalling between different chimpanzee subspecies and communities in natural environments, we showed that gestures to initiate joint travel do not represent simple innate, fully formed means, but are the result of underlying learning processes. We thus hope to inspire future studies, testing the social negotiation hypothesis and investigating whether gestural acquisition indeed involves shared understanding and mutual construction in real time by both interactants.

Acknowledgments We are indebted to C. Boesch, R. Wrangham and M. N. Muller for enabling data collection at their study sites. We thank the whole teams of the Kanyawara and Taï Chimpanzee Projects for engaging in a constructive collaboration during the fieldwork of this study. We are grateful to the Makerere University Biological Field Station (MUBFS; Uganda), the Ministère de l'Enseignement Supérieure et de la Recherche Scientifique (Côte d'Ivoire), the Office Ivoirien des Parcs et Réserves (OIPR; Côte d'Ivoire), the Uganda National Council for Science and Technology (UNCST; Uganda) and the Uganda Wildlife Authority (UWA; Uganda) for granting permission to conduct research at Kibale National Park (Uganda) and/or Taï National Park (Côte d'Ivoire). We are grateful to R. Mundry for crucial statistical advice and to G. Müller for help with the reliability coding. We thank C. Crockford, D. Dechmann, T. Deschner, D. Dominoni, B. Helm and F. Rossano for valuable discussions during the preparation of the study and the manuscript. The project was generously supported by a Dissertation Fieldwork Grant of the Wenner-Gren Foundation to M.F. and a Sofja-Kovalevskaja Award of the Humboldt Foundation to S.P. Long-term research at Kanyawara is supported by the Leakey Foundation and the U.S. National Science Foundation (Award 1355014). Open access funding was provided by the Max Planck Society (Institute for Ornithology).

Funding This study was funded by the Wenner-Gren Foundation (Grant Number 8784) and the Alexander von Humboldt Foundation (Grant Number DEU/1069105).

\section{Compliance with ethical standards}

Conflict of interest The authors declare that they have no conflict of interest.

Ethical approval All applicable international, national and/or institutional guidelines for the care and use of animals were followed. All procedures performed in studies involving animals were in accordance with the ethical standards of the chimpanzee projects at which the studies were conducted.

Open Access This article is distributed under the terms of the Creative Commons Attribution 4.0 International License (http://crea tivecommons.org/licenses/by/4.0/), which permits unrestricted use, distribution, and reproduction in any medium, provided you give appropriate credit to the original author(s) and the source, provide a link to the Creative Commons license, and indicate if changes were made.

\section{References}

Aiken LS, West SG (1991) Multiple regression: testing and interpreting interactions. Sage, Newbury Park

Altmann J (1974) Observational study of behaviour: sampling methods. Behaviour 49:227-267

Baayen RH (2008) Analyzing linguistic data. A practical introduction to statistics using R. Cambridge University Press, Cambridge 
Bandura A (1986) Social foundations of thought and action: a social cognitive theory. Prentice Hall, Princeton

Bard KA, Myowa-Yamakoshi M, Tomonaga M, Tanaka M, Costall A, Matsuzawa T (2005) Group differences in the mutual gaze of chimpanzees (Pan troglodytes). Dev Psychol 41:616-624

Bard KA, Dunbar S, Maguire-Herring V, Veira Y, Hayes KG, McDonald K (2014) Gestures and social-emotional communicative development in chimpanzee infants. Am J Primatol 76:14-29

Barr DJ, Levy R, Scheepers C, Tily HJ (2013) Random effects structure for confirmatory hypothesis testing: keep it maximal. J Mem Lang 68:255-278

Bates E (1976) Language and context: the acquisition of pragmatics. Academic Press, New York

Bates D, Maechler M, Bolker B, Walker S (2014) lme4: linear mixedeffects models using Eigen and S4 R package version 11-7

Boesch C (1991) The effects of leopard predation on grouping patterns in forest chimpanzees. Behaviour 117:220-242

Boesch C, Boesch-Achermann H (2000) The chimpanzees of the Tai Forest: behavioural ecology and evolution. Oxford University Press, Oxford

Boesch C, Marchesi P, Marchesi N, Fruth B, Joulian F (1994) Is nut cracking in wild chimpanzees a cultural behaviour? J Hum Evol 26:325-338

Bruner JS (1981) Intention in the structure of action and interaction. In: Lipsitt LP (ed) Adv Infancy Res, vol 1., AblexNorwood, New Jersey, pp 41-56

Byrne RW, Hobaiter C, Klailova M (2011) Local traditions in gorilla manual skill: evidence for observational learning of behavioral organization. Anim Cogn 14:683-693

Call J, Tomasello M (2007) The gestural communication of monkeys and apes. Lawrence Erlbaum Associates, Mahwah, New York

Call J, Tomasello M (2008) Does the chimpanzee have a theory of mind? 30 years later. Trends Cogn Sci 12:187-192

Crockford C, Boesch C (2005) Call combinations in wild chimpanzees. Behaviour 142:397-421

Crockford C, Wittig RM, Mundry R, Zuberbühler K (2012) Wild chimpanzees inform ignorant group members of danger. Curr Biol 22:142-146

De Lathouwers M, Van Elsacker L (2004) Comparing maternal styles in bonobos (Pan paniscus) and chimpanzees (Pan troglodytes). Am J Primatol 64:411-423

Dice LR (1945) Measures of the amount of ecologic association between species. Ecology 26:297-302

Dobson AJ (2002) An introduction to generalized linear models. Chapman \& Hall/CRC, Boca Raton

Field A (2005) Discovering statistics using SPSS. Sage publications, London

Fogel A, Thelen E (1987) Development of early expressive and communicative action: reinterpreting the evidence from a dynamic systems perspective. Dev Psychol 23:747-761

Forstmeier W, Schielzeth H (2011) Cryptic multiple hypotheses testing in linear models: overestimated effect sizes and the winner's curse. Behav Ecol Sociobiol 65:47-55

Furuichi $\mathrm{T}$ et al (2008) Relationships among fruit abundance, ranging rate, and party size and composition of bonobos at Wamba. In: Furuichi T, Thompson J (eds) The Bonobos. Springer, New York, pp 135-149

Gardner BT, Gardner RA (1991) Chimp-language wars. Science 252:1046

Gelman A, Su Y-S (2014) arm: data analysis using regression and multilevel hierarchical models. $\mathrm{R}$ package version 1.7-07

Genty E, Zuberbühler K (2014) Spatial reference in a bonobo gesture. Curr Biol 24:1601-1605

Genty E, Breuer T, Hobaiter C, Byrne RW (2009) Gestural communication of the gorilla (Gorilla gorilla): repertoire, intentionality and possible origins. Animal Cognition 12:527-546

Goodall J (1986) The chimpanzees of Gombe, patterns of behaviour. The Belknap Press of Harvard University Press, Cambridge

Halina M, Rossano F, Tomasello M (2013) The ontogenetic ritualization of bonobo gestures. Animal Cognition

Hewes GW (1973) Primate communication and the gestural origin of language. Curr Anthropol 12:5-24

Hobaiter C, Byrne R (2011) The gestural repertoire of the wild chimpanzee. Anim Cogn 14:745-767

Hobaiter CL, Byrne RW (2012) Gesture use in consortship: wild chimpanzees' use of gesture for an 'evolutionarily urgent'purpose. In: Pika S, Liebal K (eds) Developments in Primate Gesture Research. John Benjamins Publishing Company, Amsterdam, pp 129-146

Hobaiter C, Byrne Richard W (2014) The meanings of chimpanzee gestures. Curr Biol

King BJ (2004) The dynamic dance: nonvocal communication in African great Apes. Harvard University Press, Cambridge

Leavens DA, Hopkins WD, Bard KA (1996) Indexical and referential pointing in chimpanzees (Pan troglodytes). J Comp Psychol 110:346-353

Liebal K, Pika S, Call J, Tomasello M (2004) To move or not to move. How apes adjust to the attentional state of others. Interact Stud 5:199-219

Mead GH (1910) Social consciousness and the consciousness of meaning. Psychol Bull 7:397-405

Mitani JC, Merriwether AD, Zhang C (2000) Male affiliation, cooperation and kinship in wild chimpanzees. Anim Behav $59: 885-893$

Mundry R (2014) Statistical issues and assumptions of phylogenetic generalized least squares (PGLS). In: Garamszegi L (ed) Modern phylogenetic comparative methods and their application in evolutionary biology. Springer, Heidelberg, pp 131-153

Nishida T, Kano T, Goodall J, McGrew WC, Nakamura M (1999) Ethogram and ethnography of Mahale chimpanzees. Anthropol Sci 107:141-188

Perlman M, Tanner JE, King BJ (2012) A mother gorilla's variable use of touch to guide her infant. In: Pika S, Liebal K (eds) Developments in Primate Gesture Research, vol 6, p 55

Pika S (2008) Gestures of apes and pre-linguistic human children: similar or different? First Lang 28:116-140

Pika S (2014) Chimpanzee grooming gestures and sounds: what might they tell us about how language evolved? In: Dor D, Knight C, Lewis $\mathbf{J}$ (eds) The social origins of language: early society, communication and polymodality. Oxford University Press, Oxford, pp 129-140

Pika S (2015) Gestural communication in nonhuman species. In: Scott RA, Kosslyn SM (eds) Emerging trends in the social and behavioral sciences. Wiley, New York

Pika S, Liebal K (eds) (2012) Developments in primate gesture research. John Benjamins Publishing Company, Amsterdam

Pika S, Mitani J (2006) Referential gestural communication in wild chimpanzees (Pan troglodytes). Curr Biol 16:R191-R192

Pika S, Liebal K, Tomasello M (2003) Gestural communication in young gorillas (Gorilla gorilla): gestural repertoire, learning, and use. Am J Primatol 60:95-111

Pika S, Liebal K, Tomasello M (2005) Gestural communication in subadult bonobos (Pan paniscus): repertoire and use. Am J Primatol 65:39-61

Plooij FX (1978) Some basic traits of language in wild chimpanzees? In: Lock A (ed) Action, gesture and symbol. Academic Press, London, pp 111-131

Plooij FX (1979) How wild chimpanzee babies trigger the onset of mother-infant play. In: Bullowa M (ed) Before speech. University Press, Cambridge, pp 223-243 
Pollick AS, De Waal FBM (2007) Ape gestures and language evolution. Proc Natl Acad Sci USA 104:8184-8189

Pontzer H, Wrangham RW (2004) Climbing and the daily energy cost of locomotion in wild chimpanzees: implications for hominoid locomotor evolution. J Hum Evol 46:317-335

Quinn GP, Keough MJ (2002) Experimental design and data analysis for biologists. Cambridge University Press, Cambridge

Roberts AI, Roberts SGB, Vick S-J (2014a) The repertoire and intentionality of gestural communication in wild chimpanzees. Anim Cogn 17:317-336

Roberts AI, Vick S-J, Roberts SGB, Menzel CR (2014b) Chimpanzees modify intentional gestures to coordinate a search for hidden food. Nat Commun

Savage-Rumbaugh ES, McDonald K, Sevcic RA, Hopkins WD, Rupert E (1986) Spontaneous symbol acquisition and communicative use by pygmy chimpanzees (Pan paniscus). J Exp Psychol Gen 115:211-235

Schel AM, Townsend SW, Machanda Z, Zuberbühler K, Slocombe KE (2013) Chimpanzee alarm call production meets key criteria for intentionality. PLoS One 8:e76674

Schielzeth H (2010) Simple means to improve the interpretability of regression coefficients. Methods Ecol Evol 1:103-113

Schielzeth H, Forstmeier W (2009) Conclusions beyond support: overconfident estimates in mixed models. Behav Ecol 20:416-420

Schneider C, Call J, Liebal K (2011) Onset and early use of gestural communication in nonhuman great apes. Am J Primatol

Seyfarth RM, Cheney DL (1997) Some general features of vocal development in nonhuman primates. In: Snowdon CT, Hausberger M (eds) Social influences on vocal development. Cambridge University Press, Cambridge, pp 249-273

Slocombe KE, Waller BM, Liebal K (2011) The language void: the need for multimodality in primate communication research. Anim Behav 81:919-924

Smith WJ (1965) Message, meaning, and context in ethology. Am Nat 99:405-409

Sokal R, Rohlf F (1995) Biometry-the principles and practice of statistics in biological research, 3rd edn. Freeman \& Co., New York

Surbeck M, Mundry R, Hohmann G (2011) Mothers matter! Maternal support, dominance status and mating success in male bonobos (Pan paniscus). Proc R Soc Lond B: Biol Sci 278:590-598

Tanner JE (1993) First-year Ph.D. report MS. University of St. Andrews, St. Andrews, Scotland

Tanner JE, Patterson FG, Byrne RW (2006) The development of spontaneous gestures in zoo-living gorillas and sign-taught gorillas: from action and location to object representation. J Dev Process 1:69-102

R Core Team (2014) R: a language and environment for statistical computing. R Foundation for Statistical Computing, Vienna, Austria. http://www.Rproject.org

Tomasello M (2008) Origins of human communications. Jean Nicod Lectures. MIT Press, Cambridge

Tomasello M, Zuberbühler K (2002) Primate vocal and gestural communication. In: Bekoff M, Allen C, Burghardt GM (eds) The cognitive animal: empirical and theoretical perspectives on animal cognition. MIT Press, Cambridge, pp 293-229

Tomasello M, Call J, Nagell K, Olguin R et al (1994) The learning and use of gestural signals by young chimpanzees: a transgenerational study. Primates 35:137-154

Tomasello M, Call J, Warren J, Frost GT, Carpenter M, Nagell K (1997) The ontogeny of chimpanzee gestural signals: a comparison across groups and generations. Evol Commun 1:223-259

Tomasello M, Call J, Hare B (2003) Chimpanzees understand psychological states - the question is which ones and to what extent. Trends Cogn Sci 7:153-156

van de Pol M, Wright J (2009) A simple method for distinguishing within-versus between-subject effects using mixed models. Anim Behav 77:753-758

van de Rijt-Plooij HHC, Plooij FX (1987) Growing independence, conflict and learning in mother-infant relations in free-ranging chimpanzees. Behaviour 101:1-86

van Lawick-Goodall J (1967) Mother-offspring relationships in freeranging chimpanzees. In: Morris D (ed) Primate ethology. Weidenfeld and Nicolson, London, pp 287-346

van Schaik CP (1996) Social evolution in primates: the role of ecological factors and male behaviour. In: Proceedings of the British Academy. Oxford University Press, Oxford, pp 9-31

van Schaik CP et al (2003) Orangutan cultures and the evolution of material culture. Science 299:102-105

Watzlawick P, Bavelas JB, Jackson DDA (1967) Pragmatics of human communication. A study of interactional patterns, pathologies, and paradoxes. Norton, New York

Whiten A, Ham R (1992) On the nature and evolution of imitation in the animal kingdom: reappraisal of a century of research. Adv Study Behav 21:239-283

Whiten A et al (1999) Cultures in chimpanzees. Nature 399:682-685

Wittgenstein L (1953) Philosophical investigations. Basil Blackwell, Oxford

Wrangham RW, Clark AP, Isabirye-Basuta G (1992) Female social relationships and social organization of the Kibale Forest chimpanzees. Top Primatol 1:81-98 